\title{
AVALIAÇÃO DA FIBRONECTINA TECIDUAL EM PULMÃO DE EQUINOS COM SÍNDROME DA ASMA SEVERA EQUINA
}

(Evaluation of tissue fibronectin in lungs of equines with severe equine asthma syndrome)

${ }^{1}$ Laís Cristine Werner, ${ }^{2}$ Pedro Vicente Michelotto Junior, ${ }^{1}$ Karen Regina Lemos

UNICENTRO, Guarapuava, Paraná, Brasil. ²Pontifícia Universidade Católica do Paraná, Curitiba, Paraná, Brasil.

*Correspondência: lais.werner@cctg.com.br

RESUMO: Síndrome de asma severa equina é uma afecção respiratória de vias aéreas inferiores associada a dispneia grave em repouso e intolerância ao exercício. Apresenta quadro clínico e fisiopatológico muito semelhante à asma humana e, dentro das alterações observadas, o remodelamento da matriz extracelular (MEC) das vias aéreas é um ponto crítico. A fibronectina é uma glicoproteína adesiva que participa do processo de remodelamento e está presente transitoriamente durante o desenvolvimento ou em processos regenerativos da MEC. Este trabalho buscou analisar a distribuição e quantificá-la através de imunohistoquímica. As amostras avaliadas eram lâminas com cortes de $5 \mu \mathrm{m}$ de espessura de tecido pulmonar oriundo de sete equinos incluídos no grupo ASMA/ORVA (idade superior a 7 anos, expostos a antígenos de poeira de feno, em fase clínica de exacerbação, anamnese e avaliação clínica com quadro de esforço expiratório e dispneia em repouso, avaliação do lavado broncoalveolar com neutrofilia maior que 25\%) e de cinco animais controle (livres de histórico e aspectos clínicos relacionados a doenças respiratórias, expostos ao mesmo ambiente). $O$ método imunohistoquímico consistiu na sequência padrão de desparafinização, reativação enzimática com pepsina (S3002 Dako) por oito minutos a $37^{\circ} \mathrm{C}$, seguido de bloqueio da Peroxidase e Fosfatase Alcalina tecidual (Dako S2003) por 30 minutos. Para identificação da fibronectina foi utilizado o anticorpo primário de coelho anti-humano (CL54951AP1, Cedarlane ${ }^{\mathrm{TM}}$ ) de compatibilidade superior a 85\%, na diluição de 1:500, overnight em câmara úmida. Para a revelação da reação foi utilizado diaminobenzidina (DAB) (K03468 Dako). A captura de imagens foi executada com o auxílio de uma câmera acoplada a um microscópio Leica DM500. Para a análise de imagem utilizou-se o programa ImageJ ${ }^{\circledR}$. Dos cortes pulmonares de equino de ambos os grupos, foram fotografados 20 campos aleatórios de cada lâmina/animal com objetiva de 10x, sendo que estes apresentavam áreas alveolares, bronquiais e peribronquiais. As relações de áreas obtidas: total, branca, tecidual e marrom no tecido pulmonar foram avaliadas por relação de proporção, designada cálculo de fração volume (FV). Os dados foram analisados pelo programa estatístico Prism $7 \AA$, sendo testada a normalidade dos dados pelo teste $D^{\prime}$ Agostino $\&$ Pearson $(\alpha=0,05)$ e a comparação de médias pelo teste Welch $(P<0,05)$. A distribuição da fibronectina neste estudo foi observada na membrana basal, exclusivamente na lâmina reticular, além da distribuição em parede alveolar. Não foram demonstradas diferenças significativas nos grupos observados. Laitinen et al. (1997) descreveram que a fibronectina pode ocorrer em algumas membranas basais, mas seu papel não é claro, pois ela pode estar expressa no local durante a organogênese, mas não em adultos. Sugerindo que esta glicoproteína, apesar de sua importante função no desenvolvimento e no restabelecimento pós-injúria pulmonar, nesta fase de remodelamento das vias aéreas ou do estadiamento da obstrução nos animais estudados pode não desempenhar um papel importante, além de que diferentes fontes de fibronectina variam em suas funções e tempos de ação no pulmão.

Palavras-chave: imunohistoquímica; MEC; remodelamento.

Nota: Aprovado pelo Comitê de Ética da Universidade de Montreal sob demanda "07 - Rech 1234", em 01/01/ 2007.

Referência: LAITINEN A.; ALTRAJA A.; KAMPE M.; LINDEN M.; VIRTANEN I.; LAITINEN L. A. Tenascin is increased in airway basement membrane of asthmatics and decreased by an inhaled steroid. American Journal of Respiratory Critical Care Medicine, v.156, n.3Pt1, p.951-958, 1997. 